\title{
Friction and wear performance of glass fiber reinforced poly-ether-ether-ketone composite against different polymer counterparts
}

\begin{abstract}
In this study, the friction and wear performance of $30 \mathrm{wt} . \%$ glass fiber reinforced poly-ether-ketone $(\mathrm{PEEK}+30 \% \mathrm{GF})$ composite materials against poly-ether-imide (PEI) polymer blend and poly-phenylene-sulphide (PPS) polymer composite materials under dry sliding condition were evaluated. Friction and wear tests were carried out on a pin-disc arrangement at the sliding speed of $0.5 \mathrm{~m} / \mathrm{s}$ and under $0.707,1.41$, and 2.12(N) applied loads condition. 10wt.\% poly-tetra-fluoro-ethylene (PTFE) filled poly-ether-imide polymer blend (PEI+10\%PTFE) and 40wt.\% glass fiber reinforced poly-phenylene-sulphide (PPS $+40 \% \mathrm{GF}$ ) composite counter-face disc materials were used. The results show that the coefficient of friction and specific wear rates for PEEK $+30 \% \mathrm{GF}$ polymer composites against steel, polymer blend and polymer composite material increases slightly with the increment of applied pressure values. Finally, the specific wear rates for PEEK polymer composite against PTFE filled PEI polymer blends and glass fiber reinforced PPS composite under dry sliding conditions are in the order of $10^{-14} \mathrm{~m}^{2} / \mathrm{N}$ and $10^{-14} \mathrm{~m}^{2} / \mathrm{N}$, respectively. The results suggested that it is more convenient to use PEEK $+30 \% \mathrm{GF}$ composite against steel for tribological applications.
\end{abstract}

Keywords: PEEK, PEI, PTFE, polymer, wear, composite
Volume I Issue 5 - 2017

\author{
Huseyin Unal,Abdullah Mimaroglu, Ahmet \\ Ozel \\ Sakarya University, Faculty of Technology, Turkey
}

Correspondence: Huseyin Unal, Sakarya University, Faculty of Technology, Esentepe kampusu, Sakarya, Turkey,

Email unal@sakarya.edu.tr

Received: October 17, 2017| Published: November 30, 2017
Abbreviations: PEI, poly-ether-imide; PPS, poly-phenylenesulphide; PTFE, poly-tetra-fluoro-ethylene; PEEK, poly-ether-etherketone

\section{Introduction}

In tribological applications, because of the corrosive problems of the metals in water applications, poly-ether-ether-ketone (PEEK) and its composites are preferred for rubbing materials. As it is known PEEK is a high performance semi-crystalline thermoplastic polymer and has received significant attention in recent years. This is due to its high mechanical strength and elastic modulus, high toughness, chemical inertness, high melting temperature, easy processing, and wear resistance. Therefore, poly-ether-ether-ketone polymer material plays a more important role as a bearing and sliding material. ${ }^{1,2}$ Lots of studies on the tribological properties of PEEK have been reported..$^{3-11}$ Most studies published in the literature were in the friction and wear of polymers sliding against steels in dry conditions. The coefficient of friction can, generally, be reduced, and the wear resistance can be improved by selecting the right material combinations. ${ }^{12,13}$ Usually, tribological phenomena lead to a loss of mechanical efficiency. So, the accurate knowledge of the influence of applied load, sliding speed and contact temperature on the friction and wear is extremely important. ${ }^{14}$ The purposes of this investigation are to clarify the tribological characteristics of $30 \mathrm{wt} \%$ glass fiber reinforced poly-ether-etherketone composite sliding against poly-tetra-fluoro-ethylene (PTFE) filled poly-ether-imide (PEI) blend and $40 \%$ glass fiber reinforced PPS composite under dry sliding conditions. Tribological tests versus PTFE filled PEI blend and 40\% glass fiber reinforced PPS composite were carried out on a pin-on-disc arrangement. Tribological tests were at room temperature under $0.707 \mathrm{MPa}, 1.42 \mathrm{MPa}$ and $2.12 \mathrm{MPa}$ applied pressure and at $0.5 \mathrm{~m} / \mathrm{s}$ sliding speed. The specific wear rates were realized from mass loss and were reported.

\section{Experimental study}

In this study, the pin material used is $30 \%$ glass fiber reinforced PEEK composite. The glass fiber reinforced PEEK composite with trade name Ketron GF30 is supplied by Quadrant Engineering Plastics, Istanbul. PTFE blended PEI with granule form is supplied by GE Engineering Plastics, Istanbul. PPS $+40 \% \mathrm{GF}$ engineering polymer with granule form purchased from Chevron Phillips Chemical Co. Istanbul. Samples of six mm in diameter flat-ended pins of PEEK $+30 \%$ GF composite were machined by a revolver machine. The $5 \mathrm{~mm}$ in thickness and $100 \mathrm{~mm}$ in diameter disc materials that are PPS composite reinforced with $40 \mathrm{wt} . \%$ glass fiber and PEI blend with PTFE were produced by ordinary injection molding machine. For friction and wear tests, a pin-on-disc rig connected to a computer is used. During the tests, a transducer mounted on the loading arm measured the friction force. The readings are taken as the average of 30 readings every 60 second. For this purpose a microprocessor controlled data-acquisition system is used. Each test was carried out for a sufficient time period (33 minute) within the steady-state region. Furthermore, to ensure the reliability in the results, each test is repeated three times. After each test, the mass loss in pin was measured. The scatter in the results is small. Therefore, the average values are taken into consideration, which eliminate the essential evaluation of the sensitivity of the obtained data.

\section{Results and discussion}

Table 1 illustrates the tribotest process parameters used in the study. Figure 1 shows the variation of coefficients of friction with 
contact pressure for $30 \%$ glass fiber reinforced PEEK composite against 10\%PTFE filled PEI blend and $40 \%$ glass fiber reinforced PPS composite discs under dry sliding conditions, respectively. It is clear from this figure that the coefficients of friction values of $30 \%$ glass fiber reinforced PEEK composite are influenced by the change in applied pressure and different rubbing surface materials.

Table I The test conditions from pin-on-disc tribo test

\begin{tabular}{ll}
\hline Process parameters & Experimental conditions \\
\hline Applied pressure $(\mathrm{MPa})$ & $0.707, \mathrm{I} .4 \mathrm{I}, 2.12$ \\
Sliding speed $(\mathrm{m} / \mathrm{s})$ & 0.5 \\
Temperature $\left({ }^{\circ} \mathrm{C}\right)$ & $22 \pm 2$ \\
Humidity $(\%)$ & $59 \pm 2$ \\
Sliding distance $(\mathrm{m})$ & 1000 \\
Surface roughness $(\mathrm{Ra}, \mu \mathrm{m})$ & $0.35-0.40$
\end{tabular}

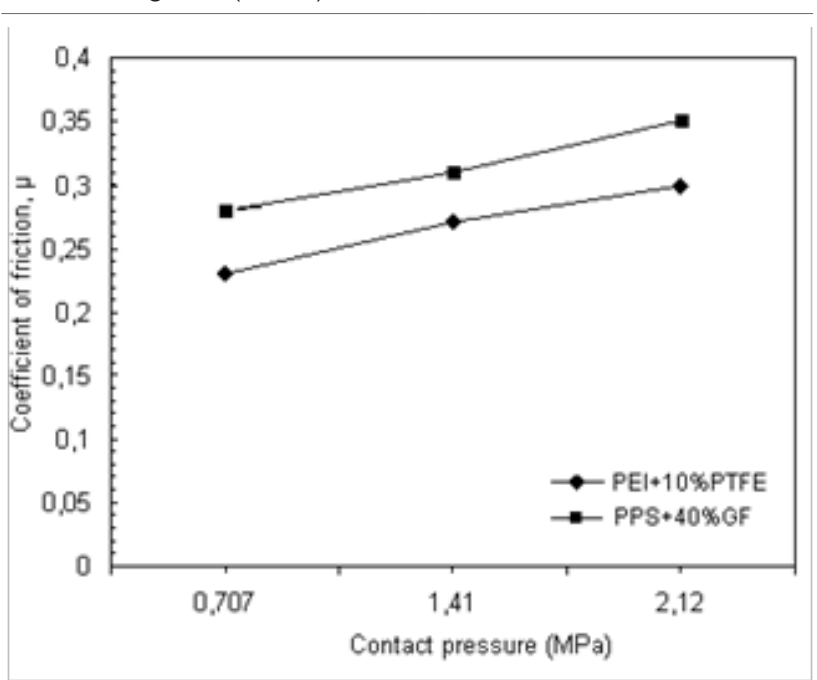

Figure I The relationship between coefficient of friction and contact pressure for $30 \%$ glass fiber reinforced PEEK composites.

The average friction coefficient of $30 \%$ glass fiber reinforced PEEK composite rubbing against 10\%PTFE filled PEI blend discs is between 0.23 and 0.30 . In rubbing against $30 \%$ glass fiber reinforced PPS composite, the coefficient of friction values for PEEK composite are between 0.28 and 0.36. As seen in Figure 1, the coefficient of friction values of PEEK composite increases with the increment of applied load values against PEI blend and PPS composite materials. There are about $30 \%$ and $28 \%$ increase in coefficient of friction with the increase in applied pressure from 0.707 to $2.12 \mathrm{MPa}$ for $30 \%$ glass fiber reinforced PEEK composite against PEI blend discs and 30\% glass fiber reinforced PPS composite disc, respectively. It is known that tribological performance of polymer and polymer composites can be associated to their visco-elastic and temperature-related properties. It is known that the sliding contact of two materials results in heat generation at asperities and hence increases in temperature. The amount of rises in temperature is influenced by the amount of heat flow. If the increase in surface temperature is high in comparison to heat deformation temperature of the material, this influences the visco-elastic property which causes softening of the materials. This causes the rubbing of glass fibers of faced materials or fiber against polymer; therefore reflect the friction and wear performance of materials. Therefore, the increase in the coefficient of friction occurs as rubbing polymer composite with polymer composite.
Figures 2 illustrates the variation of specific wear rate with applied pressure values for $30 \%$ glass fiber reinforced PEEK composite against 10\%PTFE filled PEI blend and 40\% glass fiber reinforced PPS composite discs under dry sliding conditions, respectively. The specific wear rate value of $30 \%$ glass fiber reinforced PEEK composite are influenced by applied pressure value and counter-face material.

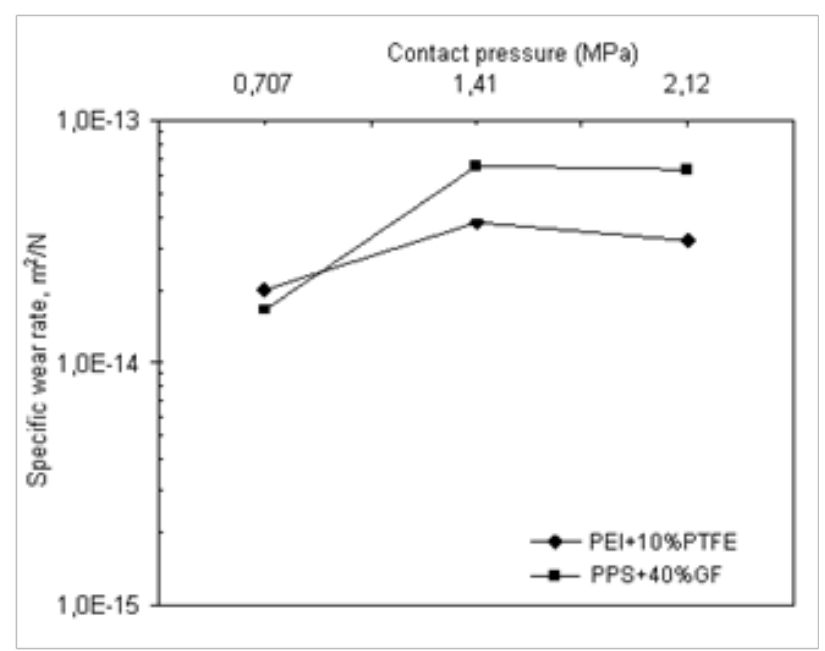

Figure 2 The relationship between specific wear rate and contact pressure for $30 \%$ glass fiber reinforced PEEK composites.

In case of rubbing against PTFE filled PEI blend and $40 \%$ glass fiber reinforced PPS composite, glass fiber reinforced PEEK composite have shown sensitivity to change in applied pressure values. The average specific wear rate values for glass fiber reinforced PEEK composite against PEI blend and PPS composite are 4.5.0x10${ }^{14}$ and $8.0 \times 10^{-14} \mathrm{~m}^{2} / \mathrm{N}$, respectively. Glass fiber reinforced PEEK composite/PTFE filled PEI blend combination shows the best tribological performance. The specific wear rate values increased with the increase in applied pressure. The increasing ratio in specific wear rate values for glass fiber PEEK composite against PEI blend and glass fiber PPS composite are $125 \%$ and $433 \%$ respectively. Glass fiber reinforced PEEK composite/PEI blend couple illustrates the best tribological performance for electrical contact breaker.

\section{Conclusion}

The study of friction and wear performance of $30 \%$ glass fiber reinforced poly-ether-ether ketone polymer composite in use in electrical applications showed that:

i. The maximum friction coefficient of poly-ether-ether ketone polymer composite reinforced with $30 \%$ glass fiber against poly-phenylene sulphide composite reinforced with $40 \%$ glass fiber disc material is 0.36 .

ii. The coefficient of friction is both large sensitive to material combinations and applied pressure.

iii. The maximum specific wear rate for PEEK $+30 \%$ glass fiber composite against poly-phenylene-sulphide composite reinforced with $40 \%$ glass fiber disc material is $8.0 \times 10^{-14} \mathrm{~m}^{2} / \mathrm{N}$.

iv. The minimum specific wear rate for PEEK $+30 \%$ glass fiber composite against glass fiber reinforced PPS composite disc material under the applied pressure of $0.707 \mathrm{MPa}$ is $1.5 \times 10$ ${ }^{14} \mathrm{~m}^{2} / \mathrm{N}$.

v. PEEK $+30 \%$ GF $/$ PEI-PTFE blend combination showed the best tribological performance for use in electrical application. 


\section{Acknowledgements}

None.

\section{Conflict of interest}

The author declares no conflict of interest.

\section{References}

1. Kausch HH. Advanced Thermoplastic Composites (Characterization and Processing). Munich, Germany: Hanser Publishers; 1993.

2. Cogswell FN. Thermoplastic Aromatic Polymer Composites. 1st ed. Oxford, USA: Butterworth-Heinemann; 1992. 288 p.

3. Lu Z, Friedrich K. On the Friction and Wear of Poly-ether-ether-ketone Composites. 1st ed. Balkan Conference on Tribology, Sofia, Bulgaria: Balkantrib; 1993. p. 1-3.

4. Karger-Kocsis J, Friedrich K. Temperature and strain-rate effects on the fracture toughness of PEEK and its short glass fiber reinforced composites. Polymer. 1986;27(11):1753-1760.

5. Talbott ME, Springer GS. The effect of crystallinity on the mechanical properties of PEEK polymer and graphite fiber reinforced PEEK. J Comp Mater. 1987;21(11):1056-1081.

6. Voss H, Friedrich K. On the wear behaviour of short fiber reinforced PEEK composites. Wear.1987;116(1):1-18.
7. Voorth JV, Bahadur S. The growth and bonding of transfer film and the role of CuS and PTFE in the tribological behaviour of PEEK. Wear. 1995;181-183(1):212-221.

8. Bahadur S, Gong D. The role of copper compounds as fillers in the transfer and wear behaviour of polyetheretherketone. Wear. 1992;154(1):151165.

9. Stolarski TA. Tribology of poly etheretherketone. Wear. 1992;158(12):71-78.

10. Lu ZP, Friedrich K. On sliding friction and wear of PEEK and its composites. Wear. 1995;181-183(2):624-631.

11. Ovaert TC, Cheng HS. The unlubricated sliding wear behaviour of polyetheretherketone against smooth mild-steel counterfaces. ASME J Tribol. 1991;113(1):150-157.

12. Yamaguchi Y. Tribology of Plastic Materials. 1st ed. Their Characteristics and Applications to Sliding Components. Amsterdam, USA: Elsevier; 1990. $361 \mathrm{p}$.

13. Hooke CJ, Kukureka SN, Liao P, et al. The friction and wear of polymers in non-conformal contacts. Wear. 1996;200(1-2):83-94.

14. Davim J. An Experimental study of the tribological behaviour of the brass/steel pair. J Mater Process Technol. 2000;100(1-3):273-277. 